\title{
Subscapularis motor point block for spastic shoulders in patients with cervical cord injury
}

\author{
$\mathrm{K}_{\text {Uchikawa }}{ }^{1}, \mathrm{H}$ Toikawa ${ }^{2}$ and $\mathrm{M} \mathrm{Liu}{ }^{2}$ \\ ${ }^{1}$ Department of Rehabilitation Medicine, National Hospital Organization, Murayama Medical Center, Tokyo, Japan \\ and ${ }^{2}$ Department of Rehabilitation Medicine, Keio University, school of Medicine, Tokyo, Japan
}

\begin{abstract}
Study design: Case series.
Objectve: The objective was to study the effect of phenol blocks to the motor points of the subscapularis muscle in patients with cervical cord injury $(\mathrm{CCl})$.

Setting: Spinal cord injury units of a national hospital in Tokyo.

Methods: The participants were seven patients with traumatic $\mathrm{CCl}$, mean age 55.8 years (SD4.0), whose injury level were at the fifth cervical level and the American Spinal Injury Association (ASIA) impairment scale was $A$ in $2, C$ in 1 and $D$ in 4 . They were at least 5 months post-acute injury, and complained of pain and limited range of motion (ROM) of their shoulder joint that were unresponsive to usual rehabilitative interventions and medications. Before and after the phenol block to the motor points of the subscapularis muscle, we compared passive and active ROM of the shoulder (flexion, abduction and external rotation), spasticity of the subscapularis as assessed with the modified Ashworth scale, pain as evaluated with a visual analog scale, and eating item of the Functional Independence Measure.

Results: There were significant improvements in passive ROM in flexion $\left(23.7^{\circ}\right)$, abduction $\left(19.4^{\circ}\right)$ and external rotation $\left(16.8^{\circ} ; P<0.05\right)$. Visual analog scale for shoulder pain was reduced from 6.0 to $3.4(P<0.05)$. The modified Ashworth scale for shoulder spasticity, however, did not significantly change. The eating Functional Independence Measure item score improved significantly $(P<0.05)$.

Conclusions: This study suggests that subscapularis motor point block for pain and limited ROM with spastic shoulder is a useful technique in patients with $\mathrm{CCl}$.

Spinal Cord (2009) 47, 249-251; doi:10.1038/sc.2008.122; pulished online 30 September 2008
\end{abstract}

Keywords: phenol block; contracture; pain; spasticity; ADL

\section{Introduction}

In persons with cervical cord injury (CCI), spasticity and pain around the shoulder joint and its consequent limitation of range of motion (ROM) can interfere with their activities of daily living (ADL), and can be an important obstructive factor to rehabilitation. The incidence of shoulder pain in acute CCI has been reported to range from 51 to $78 \%{ }^{1}$ Waring et $a .^{2}$ reported that over half of the patients developed shoulder pain within 2 weeks of the spinal injury. A higher level of CCI was associated with a higher incidence of pain. ${ }^{1}$

Shoulder pain can limit participation in rehabilitative activities and reduce the time available for functional retraining. It has been reported to increase with upper extremity dressing, transfers and reaching. ${ }^{3}$ Loss of independence can have financial consequences and increase the

Correspondence: Dr K Uchikawa, Department of Rehabilitation Medicine, Saiseikai Yokokama-shi Tobu Hospital, 3-6-1 Shimosueyoshi, Tsurumi-ku, Yokohama, Kanagawa 230-0012, Japan.

E-mail: k_uchikawa@33.netyou.jp

Received 23 April 2008; revised 4 July 2008; accepted 6 August 2008; pulished online 30 September 2008 physical burden on caregivers. Shoulder pain may, therefore, be functionally and economically equivalent to a higher lesion level. ${ }^{1,4,5}$

In particular, for those suffering from central cord syndrome, whose proximal arm function is usually disturbed from the outset, aggravation of spasticity around the shoulder can be detrimental. When these shoulder problems are not properly managed, a vicious cycle of pain, aggravation of spasticity and further limitation of ROM can intervene. In this situation, therapeutic measures, such as injection of analgesics into the shoulder joint or suprascapular nerve block would not be effective.

The rotator cuff muscles are innervated by the C4-7 segments and partial lesions at these levels can cause either lower motor or upper motor neuron lesions. When the subscapularis muscle suffer from upper motor neuron lesions, it becomes spastic and because of its spasticity usually overwhelms the relative weakness of the rest of the rotator cuff muscles, internal rotation and adduction contracture of the shoulder joint with associated pain occurs. $^{6,7}$ This can lead to the reduced external rotation 
and insufficient acromial elevation and potential tendon impingement. $^{1}$

Therefore, subscapularis motor point block can potentially be effective to remedy spastic shoulder pain in patients with CCI, but reports have been so far limited to patients with stroke. ${ }^{8-11}$ The purpose of this study is to examine the effects of subscapularis motor point block for shoulder problems in persons with CCI.

\section{Methods}

From the 130 CCI patients receiving rehabilitation therapy at spinal cord injury units of Murayama Medical Center in Tokyo during 2004-2006, we recruited seven patients with traumatic CCI according to the following criteria:

(1) The candidates were at least 5 months post-acute injury.

(2) They had marked limitation of shoulder active ROM (flexion $<60^{\circ}$, abduction $<60^{\circ}$, and external rotation $<5^{\circ}$ ) resulting from severe shoulder pain and spasticity that had not been improved with muscle relaxants, therapeutic exercise and/or shoulder joint injection.

The participants consisted of six men and 1 woman, and their mean age was 55.8 years (s.d. $=4.0$, range $=50-61$ ). All of their injury level was at the fifth cervical level (C5), and their impairment level, as classified according to the American Spinal Injury Association (ASIA), ${ }^{12}$ was A in two patients (bilateral in one patient and right in another), $\mathrm{C}$ in one patient (left side) and D in four patients (right in two patients and left in two patients).

The procedure for subscapularis motor point block followed that described by Hecht et al. ${ }^{8,9}$ The patient was positioned lying on one side, with the injection side up and arms propped to produce as much winging of the scapula as possible. The needle was inserted under the medial edge of the scapula at the level of the spine of scapula. Teflon-coated 100-mm needle (Top Corp., Tokyo, Japan) was used and slided along the anterior surface of the scapula.
To localize a motor point, weak electric stimulation (1 mA) was delivered with a chronaximeter (OG Giken Corp., Okayama, Japan) through the needle. At a point where the strongest muscle contraction was observed, $0.2-0.3 \mathrm{ml}$ of $5 \%$ phenol was injected, and successful blocking was confirmed by observing the disappearance of contraction.

Before and $24 \mathrm{~h}$ after the injection, the following outcome measures were assessed: passive and active ROM of the shoulder joint (flexion, abduction and external rotation); spasticity of shoulder flexors and external rotators as evaluated with the modified Ashworth Scale; ${ }^{13}$ shoulder pain as measured with a $10-\mathrm{cm}$ visual analog scale; muscle strength for shoulder flexion, abduction and external rotation as evaluated with the manual muscle test according to the Medical Research Council grade; ${ }^{14}$ ADL related with upper extremity functions as measured with the eating item of the Functional Independence Measure (FIM). ${ }^{15}$

The before and after measurements were compared with the paired $t$-test and the Wilcoxon signed-rank test using a statistical software Statcel (OMS, Saitama, Japan) for Windows. The level of significance was set at $P<0.05$.

The study was approved by the institutional ethics review board of our facility. The purpose and procedures of the study were fully explained, and informed consent was obtained from the participants.

\section{Results}

All the motor point blocks were performed without complications. As demonstrated in Table 1, statistically significant improvement was observed for passive ROM of shoulder flexion $\left(23.7^{\circ}\right)$, abduction $\left(19.4^{\circ}\right)$ and external rotation $\left(16.3^{\circ}\right.$; paired $t$-test, $\left.P<0.05\right)$. The visual analog scale for shoulder pain improved from 6.0 to 3.4 (paired $t$-test, $P<0.05)$. The modified Ashworth scale ratings, which scored 3 in all cases before the injection, did not significantly change after the injection. The manual muscle test ratings also did not change significantly for flexion, abduction and external rotation (Wilcoxon signed-ranks test, not signifi-

Table 1 The effects of motor point block of the subscapularis muscle

\begin{tabular}{|c|c|c|c|c|c|c|c|c|}
\hline Subject (age, side) & $\begin{array}{l}\text { 1(59, left) } \\
\text { Before/after }\end{array}$ & $\begin{array}{l}2(61, \text { left }) \\
\text { Before/after }\end{array}$ & $\begin{array}{l}3(58, \text { right }) \\
\text { Before/after }\end{array}$ & $\begin{array}{c}3(58, \text { left }) \\
\text { Before/after }\end{array}$ & $\begin{array}{l}4(50, \text { right }) \\
\text { Before/after }\end{array}$ & $\begin{array}{c}5(52, \text { left }) \\
\text { Before/after }\end{array}$ & $\begin{array}{l}\text { 6(52,right } \\
\text { Before/after }\end{array}$ & $\begin{array}{l}7(56, \text { right }) \\
\text { Before/after }\end{array}$ \\
\hline Flexion* & $90 / 105$ & $50 / 60$ & $90 / 110$ & $70 / 95$ & $30 / 90$ & $85 / 95$ & $75 / 90$ & $45 / 80$ \\
\hline Passive ROM abduction* & $75 / 95$ & $40 / 55$ & $65 / 90$ & $65 / 100$ & $70 / 80$ & $80 / 85$ & $65 / 75$ & $65 / 100$ \\
\hline $\mathrm{ER}^{*}$ & $5 / 10$ & $-20 / 0$ & $25 / 40$ & $15 / 40$ & $10 / 30$ & $-10 / 0$ & $25 / 35$ & $0 / 25$ \\
\hline Flexion & $55 / 80$ & $30 / 40$ & $30 / 35$ & $15 / 15$ & $20 / 45$ & $15 / 15$ & $20 / 70$ & $30 / 60$ \\
\hline Active ROM abduction & $55 / 80$ & $30 / 40$ & $20 / 30$ & $20 / 20$ & $45 / 60$ & $55 / 65$ & $20 / 30$ & $20 / 50$ \\
\hline ER & $0 / 0$ & $-30 /-15$ & $5 / 5$ & $5 / 5$ & $0 / 20$ & $-40 /-20$ & $-10 / 0$ & $-15 / 0$ \\
\hline Flexion & $3-/ 3-$ & $3-/ 3-$ & $3-/ 3-$ & $2 / 2$ & $2 / 2$ & $2 / 2$ & $2 / 3-$ & $3-13-$ \\
\hline MMT abduction & $3-/ 3-$ & $3-/ 3-$ & $3-/ 3-$ & $2 / 2$ & $3-/ 31$ & $2 / 2$ & $2 / 2$ & $2 / 3-$ \\
\hline ER & $1 / 1$ & $1 / 2$ & $2 / 2$ & $1 / 1$ & $1 / 2$ & $1 / 2$ & $1 / 2$ & $1 / 2$ \\
\hline MAS & $3 / 3$ & $3 / 3$ & $3 / 3$ & $3 / 3$ & $3 / 3$ & $3 / 3$ & $3 / 3$ & $3 / 3$ \\
\hline VAS $^{\#}$ & $5 / 3$ & $7 / 3$ & $5 / 4$ & $5 / 5$ & $5 / 2$ & $8 / 5$ & $10 / 2$ & $8 / 3$ \\
\hline Eating FIM item ${ }^{\#}$ & $2 / 5$ & $2 / 5$ & $1 / 5$ & $1 / 5$ & $2 / 6$ & $1 / 5$ & $4 / 6$ & $4 / 6$ \\
\hline
\end{tabular}

Abbreviations: ER, external rotation; FIM, Functional Independence Measure; MAS, modified Ashworth scale; MMT, manual muscle test; ROM, range of motion; VAS, visual analog scale.

*Paired $t$-test, $P<0.05$.

\#Wilcoxon signed-ranks test, $P<0.05$. 
cant). The eating item score of the functional independence measure improved significantly from 2.3 to 5.4 (Wilcoxon signed-ranks test, $P<0.05)$, that is, from the assistance levels to supervision or independent levels.

\section{Discussion}

Problems around the shoulder joint, including pain, functional limitations and their social impact have not been studied sufficiently in patients with CCI, and little is known about their appropriate management and its outcomes. ${ }^{16}$ Many patients seek medical treatment for pain, and receive physical therapy, pharmacological treatment or massage. ${ }^{16}$ Botulinum toxin injection is currently a popular treatment modality for spasticity, ${ }^{17}$ but reports are limited on how to inject it into the subscapularis muscle. ${ }^{6}$ Furthermore, it is not approved to use for shoulder spasticity in Japan.

Subscapularis motor point block for spastic shoulder pain is reported in patients with stroke. ${ }^{8-11}$ But as far as we know, our study is the first to report its application to patients with CCI. When patients with CCI have contractures and pain in the shoulder joint, ADL to upper extremity, such as eating, grooming and dressing can be restricted. ${ }^{18}$ This can be improved with improvement in shoulder ROM and reduction in spasticity. In our study, eating had been difficult in all patients before the intervention. After the subscapularis motor point block, however, shoulder ROM and spasticity improved, and eating became more independent.

Hecht et al. ${ }^{8,9}$ described subscapular nerve block in painful hemiplegic shoulder. They reported that stroke patients demonstrated more excessive contraction of the subscapularis muscle during shoulder flexion as compared with healthy controls, and that shoulder pain with severe spasticity was improved with subscapularis motor point block. Hara et al. ${ }^{10}$ also showed in 11 patients with spastic hemiparetic stroke that percutaneous phenol blocks to the motor points of the subscapularis muscle was a useful technique to remedy their shoulder pain and limited active shoulder movement.

The subscapularis muscle acts as a shoulder internal rotator and controls anterior dislocation of the humeral head. ${ }^{19}$ Moreover, it is innervated by upper and lower subscapular nerves. ${ }^{19}$ The upper subscapular nerve is composed of more than two branches. Therefore, the positions and the number of motor points of subscapularis vary individually, which makes it difficult to search for the motor points.

Furthermore, there is a problem of blind puncture in the motor point block to the subscapularis muscle. If one does not carefully confirm the point of the needle, there is a risk of pneumothrax. Moreover, hemorrhage is a potential complication. ${ }^{8}$ To avoid these complications, it is necessary to make the paretic scapula wing as much as possible, so that enough space is created between the medial edge of the scapula spine and trapezius muscle. Through this space, we punctured the needle into the subscapularis muscle to the direction of acromion. With this procedure, the risk of complications could be reduced.

Chiodo et al. $^{20}$ reported three approaches for needle insertion into the subscapular muscle - a posterior axillary approach, a medial scapular approach and a superior scapular approach. They described that the posterior axillary approach was the most effective compared with other two approaches. However, they reported that subscapular motor point block was difficult with all the three approaches tested. In our study, we used the medial approach based on Hecht et al., ${ }^{8,9}$ and obtained improvement in several of the outcome measures without complications.

In conclusion, although this was a small sample size study without controls, motor point blocks to the subscapularis muscle could be effective to improve upper extremity related ADL by improving limited ROM and pain of the shoulder joint in persons with CCI.

\section{References}

1 Salisbury S, Low Choy N, Nitz J. Shoulder pain, range of motion and functional motor skills after acute tetraplegia. Arch Phys Med Rehabil 2003; 84: 1480-1485.

2 Waring WP, Maynard FM. Shoulder pain in acute traumatic quadriplegia. Paraplegia 1991; 29: 37-42.

3 Subbarao J, Klopfstein J, Turpin R. Prevalence and impact of wrist and shoulder pain in patients with spinal cord injury. $J$ Spinal Cord Med 1995; 18: 9-13.

4 Sie I, Waters R, Adkins R, Gelluman H. Upper extremity pain in the postrehabilitation spinal cord injured patient. Arch Phys Med Rehabil 1992; 73: 44-48.

5 Salisbury S, Nitz J, Souvlis T. Shoulder pain following tetraplegia: a follow-up study 2-4 years after injury. Spinal Cord 2006; 44: 723-728.

6 Harrison TP, Sadnicka A, Eastwood DM. Motor point for the neuromuscular blockade of the subscapularis muscle. Arch Phys Med Rehabil 2007; 88: 295-297.

7 Yelnik AP, Colle FM, Bonan IV. Treatment of pain and limited movement of the shoulder in hemiplegic patients with botulinum toxin A in the subscapular muscle. Eur Neurol 2003; 50: 91-93.

8 Chironna RC, Hecht JS. Subscapularis motor point block for the painful hemiplegic shoulder. Arch Phys Med Rehabil 1990; 71: 428-429.

9 Hecht JS. Subscapular nerve block in the painful hemiplegic shoulder. Arch Phys Med Rehabil 1992; 73: 1036-1039.

10 Hara Y, Chino N, Noda Y, Mihara B. Subscapularis motor point block in shoulder contracture among stroke patients (in Japanese). Jpn J Rehabil Med 1997; 34: 693-696.

11 van Kuijk AA, Geurts AC, Bevaart BJ, van Limbeek J. Treatment of upper extremity spasticity in stroke patients by focal neuronal or neuromuscular blockade: a systematic review of the literature. J Rehabil Med 2002; 34: 51-61.

12 Maynard Jr FM, Bracken MB, Creasey G, Ditunno Jr JF, Donovan WH, Ducker TB et al. International standards for neurological and functional classification of spinal cord injury. American Spinal Injury Association. Spinal Cord 1997; 35: 266-274.

13 Bohannon RW, Smith MB. Interrater reliability of a modified Ashworth score of muscle spasticity. Phys Ther 1987; 67: 206-207.

14 Medical Research Council. Aids to the investigation of peripheral nerve injuries. Her Majesty's Stationery Office: London, England, 1976.

15 Stinemam MG, Shea JA, Jette A, Tassoni CJ, Ottenbacher KJ et al. The Funcutional Independence Measure: tests of scaling assumptions, structure, and reliability across 20 diverse impairment categories. Arch Phys Med Rehabil 1996; 77: 1291-1294.

16 Dalyan M, Cardenas DD, Gerard B. Upper extremity pain after spinal cord injury. Spinal Cord 1999; 37: 191-195.

17 Davis EC, Baarnes MP. Botulinum toxin and spasticity. J Neurol Neurosurg Psychiatry 2000; 69: 143-147.

18 Dalyan M, Sherman A, Cardenas DD. Factors associated with contractures in acute spinal cord injury. Spinal Cord 1998; 36: 405-408.

19 Hollinshead WH. The Functional Anatomy: The Back and Limbs, 3rd edn. Harper \& Row: Philadelphia, 1982, pp 313-314.

20 Chiodo A, Goodmurphy C, Haig A. Cadaveric study of methods for subscapularis muscle needle insertion. Am J Phys Med Rehabil 2005; 84: 662-665. 